\title{
LERO - An Extensible and Adaptive Remote Lab for Educational Robotics
}

\author{
Crijina Chagas Flores ${ }^{1,2}$, Artur Kronbauer ${ }^{2,3}$, Jorge Campos ${ }^{2,4}$ \\ ${ }^{1}$ Instituto Federal da Bahia (IFBA) - 45078-900 - Vitória da Conquista - BA - Brasil \\ ${ }^{2}$ Programa de Pós-Graduação em Sistemas e Computação (PPGCOMP) - Universidade \\ Salvador (UNIFACS) - 41.770-235 - Salvador - BA - Brasil \\ ${ }^{3}$ Departamento de Ciências Exatas e da Terra (DCET II) - Universidade do Estado da \\ Bahia (UNEB) - 48.100-000 - Alagoinhas - BA - Brasil \\ ${ }^{4}$ Departamento de Ciências Exatas e da Terra (DCET I) - Universidade do Estado da \\ Bahia (UNEB) - 41.150-000 - Salvador - BA - Brasil \\ crijina@yahoo.com.br, arturhk@unifacs.br, jorge@unifacs.br
}

\begin{abstract}
This paper introduces the Remote Laboratory for Educational Robotics (LERO) that aims at supporting the teaching and learning process of Programming and Robotics skills of students at different ages. LERO is a Web-based, adaptable and extensible environment. The term extensible is used to characterize the ability of the system to incorporated programming blocks with new functionalities using the LERO development environment itself. The term adaptable illustrates the feature to serve a diverse audience with varied level of knowledge and experience, both in terms of programming logic and robotics.
\end{abstract}

Resumo. Este artigo apresenta o Laboratório de Robótica Educacional (LERO) que tem como objetivo apoiar o ensino de Lógica de Programação e Robótica, para estudantes de diferentes faixas etárias. O LERO é um sistema Web extensivel e adaptável. $O$ caráter extensivel se refere a capacidade do sistema incorporar blocos de programação representando novas funcionalidades utilizando o próprio ambiente desenvolvimento do LERO. O caráter adaptável se refere a capacidade de servir a diferentes públicos, tanto no que se refere a experiência em lógica de programação, quanto a habilidade de programar robôs.

\section{Introdução}

O uso da robótica em ambientes educacionais já demonstrou ser uma ferramenta que favorece o processo de ensino-aprendizagem através de atividades lúdicas e que propicia a relação entre conteúdos de diferentes áreas do conhecimento [Bagnall, 2007]. Além disso, a robótica favorece o desenvolvimento do raciocínio lógico, incentiva o trabalho autônomo e em grupo, estimula a criatividade de forma lúdica e motiva a associação da teoria à prática [Pio et al., 2007]. 
VII Congresso Brasileiro de Informática na Educação (CBIE 2018)

Anais do XXIX Simpósio Brasileiro de Informática na Educação (SBIE 2018)

Os problemas para a popularização de ambientes de robótica educacional estão relacionados aos custos para aquisição dos equipamentos, a complexidade de implantação da infraestrutura e a capacitação de profissionais para orientar práticas e experimentos. Uma forma de minimizar os problemas é disponibilizar o acesso a laboratórios virtuais ou remotos de robótica. Em uma realidade em que muitos laboratórios de informática de escolas públicas se encontram subutilizados por falta de conteúdos educacionais e pessoal qualificado, a robótica educacional pode contribuir para o desenvolvimento de atividades práticas que auxiliem no processo de ensinoaprendizagem dos alunos [Fiorio et al., 2014].

Diante desse cenário, este artigo apresenta o LERO, que é um laboratório que possibilita o acesso remoto e pode ser compartilhado por diversas instituições de ensino. Seus principais diferenciais são: (i) ser um ambiente extensível e adaptável, direcionado a diferentes públicos; (ii) disponibilizar uma plataforma robótica real; (iii) ter um ambiente de programação em blocos; (iv) oferecer diferentes visões do sistema, onde cada visão apresenta níveis diferentes de abstração das funcionalidades robóticas disponíveis; e (v) possibilitar que sejam expandidas as suas funcionalidades básicas utilizando as próprias metáforas do ambiente para criar funcionalidades mais avançadas.

O restante deste artigo está organizado em cinco Seções. A Seção 2 discute os trabalhos relacionados na área de robótica educacional. Na Seção 3, é apresentada a metodologia que norteou os estudos. A Seção 4 descreve o projeto e os componentes da sua arquitetura. Na Seção 5, são discutidas as diversas faces do ambiente LERO. Por fim, a Seção 6 apresenta as conclusões e futuros trabalhos.

\section{Laboratórios de Robótica Remotos}

Os laboratórios de robótica não presenciais podem ser divididos em dois grandes grupos: os laboratórios virtuais [Oliveira et al., 2014] e os laboratórios remotos. Nos laboratórios virtuais, toda a infraestrutura robótica é digital, isto é, os robôs são modelos bi ou tridimensionais criados no computador. Os laboratórios remotos, por outro lado, contam com uma infraestrutura robótica física. Como o LERO é um laboratório remoto, serão discutidos nesta seção apenas trabalhos que se enquadram neste grupo.

O Ambiente Telerobótico Educacional (ATE) é um laboratório remoto de robótica educacional que tem como objetivo aprimorar as habilidades do aluno na manipulação de um robô. À medida que o estudante interage com o ambiente, mensagens de seu desempenho vão sendo mostradas e sugestões para melhorá-lo vão sendo apresentadas na tela do sistema [Souza et al., 2011]. Como limitações pode se destacar os seguintes aspectos: (i) o sistema só contempla uma ação de cada vez; (ii) o conjunto de ações individuais ofertadas é bastante limitado; e (iii) o sistema não suporta a extensão das funcionalidades existentes.

O projeto desenvolvido por [Iturrate et al., 2013], apresenta um laboratório remoto que permite que o usuário controle um robô em um labirinto ou participe de um jogo interativo. Esse ambiente é interessante por oferecer dois cenários para o usuário: um que possui ações pré-definidas; e outro que permite que o usuário trabalhe com um ambiente de blocos que podem ser utilizados para modificar as ações sequenciais do experimento. Entretanto, os blocos são pré-estabelecidos e não permite que o usuário acrescente novas funcionalidades ao sistema. 
VII Congresso Brasileiro de Informática na Educação (CBIE 2018)

Anais do XXIX Simpósio Brasileiro de Informática na Educação (SBIE 2018)

O projeto m-laboratório [Granado et al., 2013] propõe um laboratório controlado por dispositivos móveis. Este projeto foi desenvolvido para a realização dos experimentos de uma disciplina de automação industrial. Os experimentos são montados no laboratório da disciplina e os alunos podem executá-los através dos seus smartphones com um servidor conectado aos equipamentos da rede de automação. $\mathrm{O}$ sistema permite cadastrar alunos e manter o histórico dos experimentos. Como pontos negativos pode-se destacar a necessidade dos usuários estarem fisicamente próximo ao servidor, já que a comunicação é feita através de uma rede local; e a ausência de um mecanismo de visualização das instalações do laboratório físico. A interface gráfica da aplicação apresenta somente a leitura das variáveis de controle.

O sistema RoboBlock [Ângulo et al., 2017] é um laboratório remoto com a programação de robôs baseada em blocos e conexão via internet. O RoboBlock, oferece um conjunto de funcionalidades compatíveis com alunos do segundo grau. A iniciativa RoboBlock se assemelha a versão do LERO adolescente, discutida nas próximas seções.

A maioria dos trabalhos analisados abordam ambientes de robótica educacional voltados para crianças e adolescentes. A disponibilização de ações sequenciais e programação em blocos predominam nesse contexto e fornecem um ambiente mais intuitivo e simples para a construção do conhecimento. Outra característica comum a todos os trabalhos apresentados é a incapacidade de incorporar novas funcionalidades aos ambientes. Esta característica restringe a capacidade dos alunos de criarem novos experimentos, limita o aprimoramento da lógica de programação e inviabiliza a utilização de novos sensores ou outros recursos robóticos. Neste sentido, o LERO, apresentado na próxima seção, foi concebido como forma de atenuar as principais deficiências encontradas nos laboratórios remotos de robótica.

\section{Metodologia}

Segundo Gil (2000) as pesquisas científicas podem ser classificadas segundo dois critérios: quanto aos objetivos e quanto aos procedimentos técnicos. Tendo em vista os objetivos deste trabalho, optou-se por utilizar os tipos descritos na Tabela 1.

Tabela 1. Quadro metodológico.

\begin{tabular}{|c|c|}
\hline QUANTO AOS OBJETIVOS & QUANTO AOS PROCEDIMENTOS TÉCNICOS \\
\hline $\begin{array}{c}\text { Exploratória - Compreender } \\
\text { conceitos lúdicos que possam } \\
\text { ajudar na programação. }\end{array}$ & $\begin{array}{c}\text { Levantamento bibliográfico - Identificar os } \\
\text { trabalhos que utilizam laboratórios remotos de } \\
\text { robótica educacional. }\end{array}$ \\
\hline $\begin{array}{c}\text { Explicativa - Utilizar } \\
\text { experimentos com robótica para } \\
\text { explicar lógica de programação. }\end{array}$ & $\begin{array}{c}\text { Estudo experimental - Realizar uma prova de } \\
\text { conceito para verificar as potencialidades e } \\
\text { limitações do ambiente LERO. }\end{array}$ \\
\hline
\end{tabular}

A primeira etapa da pesquisa refere-se a uma revisão bibliográfica preliminar sobre o ensino de programação, onde foi percebida a associação de algumas iniciativas com a utilização de programação em blocos. Essa percepção motivou o estudo da ludicidade no aprendizado de lógica de programação e robótica. Os resultados deste estudo serviram como fundamentação teórica e requisitos funcionais e não funcionais para a criação de um ambiente de desenvolvimento baseado em blocos, voltados para a 
VII Congresso Brasileiro de Informática na Educação (CBIE 2018)

Anais do XXIX Simpósio Brasileiro de Informática na Educação (SBIE 2018)

programação de robótica. A etapa final do trabalho consistiu em avaliar e validar o modelo por meio da realização de um estudo de caso.

\section{Arquitetura LERO}

O ambiente LERO tem como objetivo contribuir com o processo de ensinoaprendizagem de programação de computadores e robótica para diferentes faixas etárias, estimulando e diversificando a aquisição de conhecimentos. Este ambiente permite que os usuários tenham acesso a experimentos e equipamentos reais através da Internet.

A metodologia utilizada no desenvolvimento do ambiente LERO tem como objetivo garantir o caráter inovador através do oferecimento de um sistema adaptável e extensível, ao tempo em que utiliza conceitos e metáforas de programação e robótica amplamente testadas e relatadas na literatura da área da informática educacional [Bezerra Neto, 2015]. O LERO utiliza a metáfora de programação em blocos como base de um sistema extensível e adaptável ao nível de conhecimento e experiência do usuário. O termo extensível é usado para caracterizar a capacidade que o sistema possui de permitir que novos blocos de construção sejam incorporados ao ambiente. Blocos com complexidade crescente são desenvolvidos e incorporados através da utilização do próprio ambiente de desenvolvimento LERO. Já o termo adaptável ilustra a característica que o sistema possui de atender a um público com nível de conhecimento e experiência variada, tanto no que se refere à lógica de programação, quanto aos conhecimentos em robótica. A arquitetura do sistema pode ser contemplada na Figura 1.

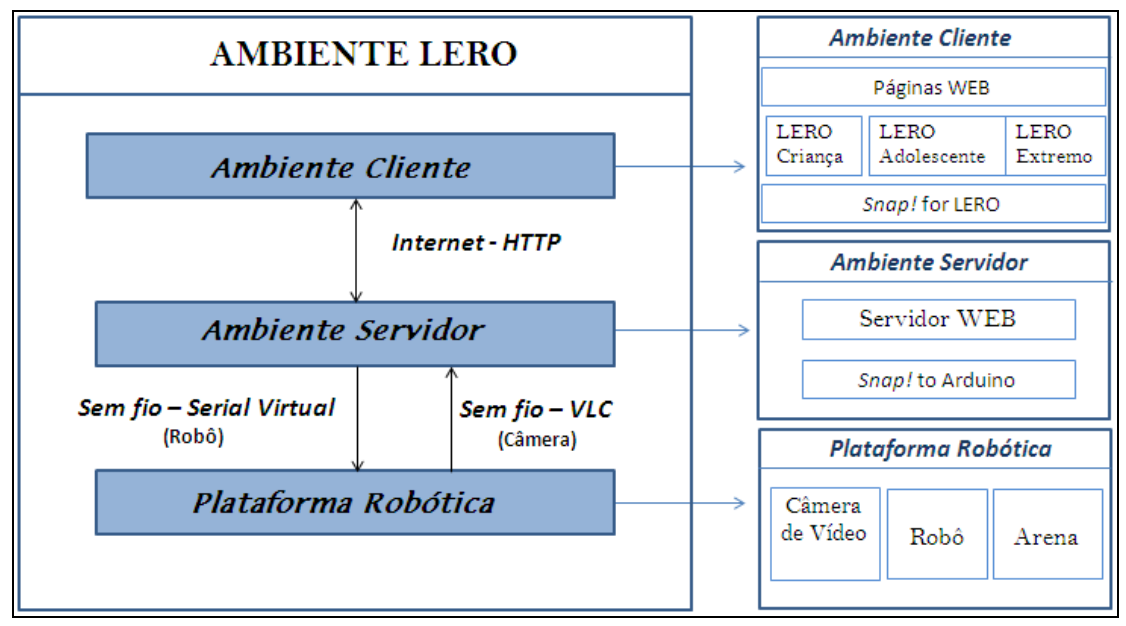

Figura 1. Arquitetura do ambiente LERO.

A arquitetura do sistema LERO é dividida em três componentes: o Ambiente Cliente, o Ambiente Servidor e a Plataforma Robótica. O Ambiente Cliente é composto por uma aplicação Web. Desta forma, o cliente LERO é naturalmente multiplataforma, podendo ser executado a partir de qualquer navegador, independente do sistema operacional.

O Ambiente Cliente provê diferentes visões dos recursos e funcionalidades disponibilizadas no sistema. A visão LERO Criança, desenvolvida para usuários na faixa etária de 8 a 12 anos, possui blocos de construção mais abstratos, com funcionalidades próximas a comandos ou verbos usuais para esta faixa etária. A visão LERO Adolescente, feita para usuários na faixa etária de 13 a 17 anos, permite trabalhar 
VII Congresso Brasileiro de Informática na Educação (CBIE 2018)

Anais do XXIX Simpósio Brasileiro de Informática na Educação (SBIE 2018)

princípios mais avançados de lógica de programação. As estruturas de controle de fluxo, variáveis e funções, por exemplo, estão presentes no ambiente e podem ser utilizadas para programar comportamentos mais elaborados para o robô. Já a visão LERO Extremo é um ambiente direcionado ao público com idade acima de 18 anos, normalmente estudantes de graduação ou pós-graduação. Nessa visão, o usuário pode estender as funcionalidades do ambiente criando seus próprios blocos, tendo como ferramenta de desenvolvimento o próprio ambiente LERO e como material de apoio pedagógico um tutorial presente no ambiente.

Independente da visão utilizada, o cliente LERO disponibiliza como ambiente de desenvolvimento uma adaptação do ambiente Snap! [Snap, 2016]. O Snap! é uma linguagem visual de programação que utiliza a metáfora de blocos de construção para permitir que o aluno possa criar programas, animações e jogos, enquanto assimila conceitos matemáticos e de programação. A adaptação do Snap!, denominada de Snap! For LERO, possui blocos de construção especializados para definição de ações e movimentações de um robô.

O Ambiente Servidor hospeda o servidor WEB que gerencia a base de dados de usuários, controla o acesso simultâneo e traduz a programação realizada pelo cliente em instruções de baixo nível, compatíveis com a plataforma robótica. A conversão da programação em blocos para instruções compatíveis com um robô Arduino [Yorinks, 2014] é feita através de uma extensão escrita em Python chamada Snap! to Arduino (S2A) [S2A, 2016]. Com a extensão S2A é possível além de converter as instruções Snap!, enviar as ações a serem executadas para o robô através de uma conexão sem fio.

Finalmente, a plataforma robótica da arquitetura LERO é composta pelo robô, uma câmera de vídeo e uma arena para movimentação do robô. A câmera de vídeo é utilizada para observar a movimentação do robô. A imagem capturada pela câmera é transmitida ao servidor Web e este faz a retransmissão do fluxo de imagens para o cliente LERO.

A título de exemplo e prova de conceito, foi criado um ambiente de teste composto por um robô e uma arena de teste. $\mathrm{O}$ robô, denominado Lerobô, foi montado com o Kit de Chassi Magician DG007 e possui quatro sensores de ultrassom, um drive para controle de motor, um Arduino Uno e um Shield de comunicação Wireless (Figura 2A). Já a arena possui a dimensão de $1,5 \mathrm{~m} \times 1,5 \mathrm{~m}$ em piso de fórmica na cor branca com divisões de madeira formando um labirinto (Figura 2B).
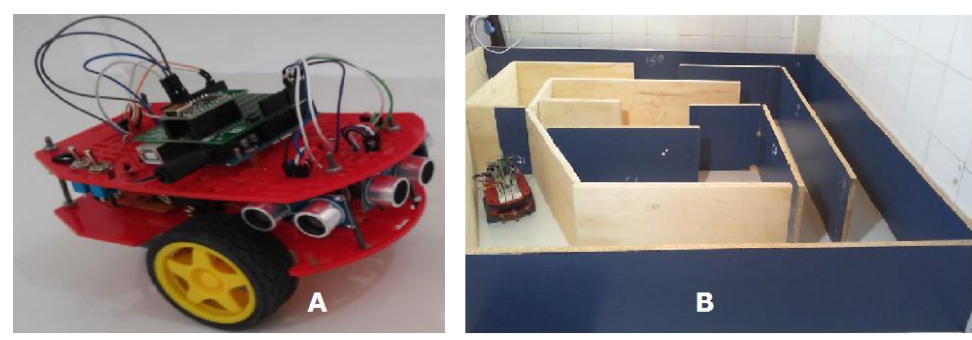

Figura 2. Plataforma Robótica do Ambiente LERO.

\section{As Diversas Faces do LERO}

As diferentes visões do ambiente LERO cliente compartilham a mesma estrutura para a interface gráfica com o usuário. De forma simplificada, qualquer versão do cliente 
VII Congresso Brasileiro de Informática na Educação (CBIE 2018)

Anais do XXIX Simpósio Brasileiro de Informática na Educação (SBIE 2018)

LERO é dividida em três grandes seções: A seção de funcionalidades (Figura 3A), uma seção de roteiros (Figura 3B) e uma janela para apresentação de um vídeo em tempo real apresentando a execução do experimento (Figura 3C).

A visão LERO Criança disponibiliza elementos simples e intuitivos para que o usuário tenha como foco a aprendizagem do raciocínio lógico e da percepção espacial e possa desenvolver sua criatividade de uma forma lúdica e motivadora. A seção de funcionalidades, localizada na Figura 3A, apresenta somente quatro grupos de funções: Movimento, Aparência, Som e Controle.

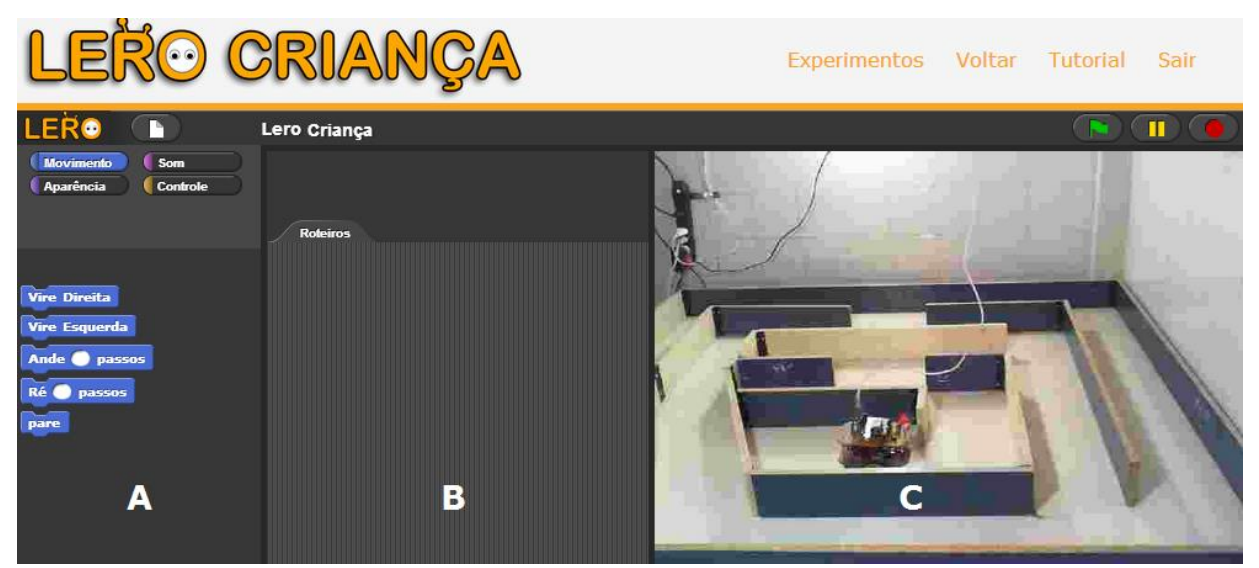

Figura 3. Ambiente Cliente: Interface gráfica da versão LERO Criança.

O grupo Movimento possui blocos que possibilitam diversos tipos de movimentações do robô, dependendo da modalidade do experimento. Como o experimento disponibilizado no nosso estudo de caso é um labirinto, só existem blocos que são compatíveis com a movimentação do robô neste tipo de experimento, são eles: Vire Direita, Vire Esquerda, Ande $\mathrm{N}$ passos, Ré $\mathrm{N}$ passos e Pare (Figura 4A).

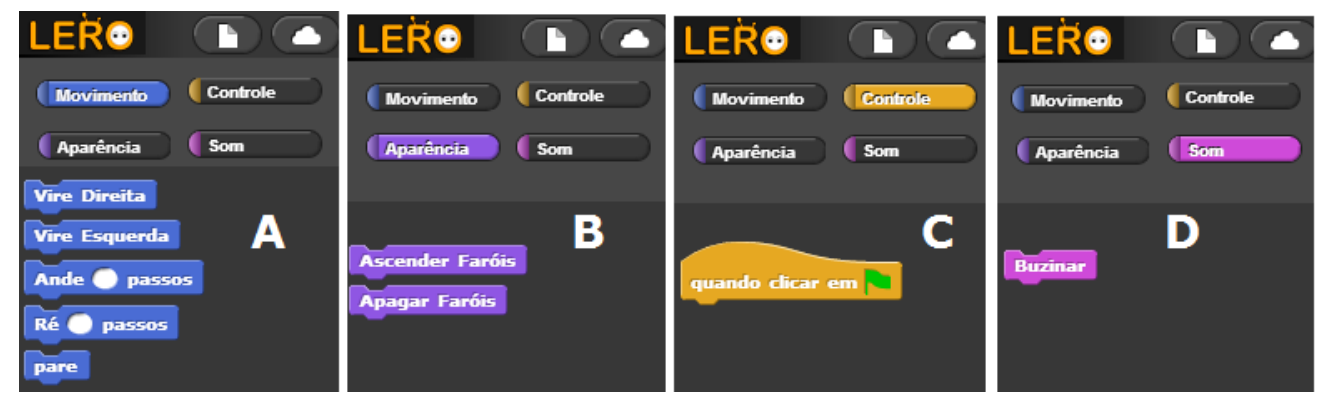

Figura 4. Detalhe da aba de funcionalidades da visão LERO Criança.

O grupo Aparência (Figura 4B) possui ações que permitem aos usuários acionarem algum equipamento que produza um efeito visual no robô. $\mathrm{Na}$ atual plataforma robótica o único efeito visual disponível é apagar e acender um pequeno farol instalado na parte frontal do robô. Desta forma, o grupo aparência possui somente os blocos Acender Faróis e Apagar Faróis.

O grupo Controle (Figura 4C) possui um único bloco. Este bloco deve ser colocado sempre no início de cada roteiro e traduz a ação de começar a executar os comandos quando o usuário clicar na bandeira verde. 
VII Congresso Brasileiro de Informática na Educação (CBIE 2018)

Anais do XXIX Simpósio Brasileiro de Informática na Educação (SBIE 2018)

O grupo Som (Figura 4D) disponibiliza blocos direcionados a execução de efeitos sonoros. Na plataforma robótica disponibilizada, o robô possui somente uma buzina, desta forma, o único bloco disponível no ambiente é o Buzinar.

A medida que o usuário seleciona os blocos de construção e monta o comportamento do seu robô, o diagrama de blocos, na aba de roteiros, vai sendo atualizado com as ações selecionadas. A interface do cliente LERO utiliza o recurso arrastar e soltar para incluir e posicionar uma nova ação no roteiro. A Figura 5A ilustra um roteiro que começa com o bloco do grupo controle, seguido por uma sequência de quatro blocos do grupo movimento. O roteiro instrui o robô a andar dez passos, virar à direita, andar mais cinco passos e por fim virar à esquerda. Para transferir os comandos do roteiro para o robô e visualizar a execução das manobras, o usuário deverá utilizar a região de visualização de experimentos, situada no lado direto da interface (Figura 5B).

É importante salientar que nem todas as ações programadas pelo usuário podem ser executadas pelo robô. A ação incluída no roteiro que determina que o robô ande dez passos, por exemplo, pode não ocorrer caso o robô detecte algum obstáculo à sua frente, tal como, uma parede ou qualquer outro objeto colocado no caminho do labirinto do experimento em questão. Caso isso aconteça, o robô evita o choque interrompendo o seu movimento, o ambiente emite uma notificação informando que o experimento não foi bem-sucedido e convida o usuário a modificar o roteiro para corrigir o problema.

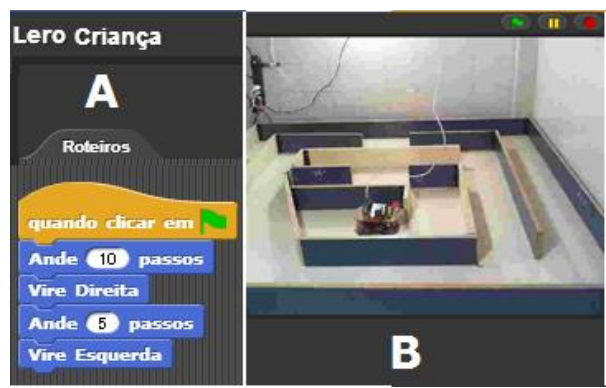

Figura 5. Visão parcial do LERO Criança.

Para alunos do ensino médio ou de cursos introdutórios de nível superior, o ambiente LERO oferece a visão Adolescente. Na visão LERO Adolescente, as funcionalidades do LERO Criança são acrescidas de novos blocos de ações com menor grau de abstração, isto é, com comandos que permitem operar diretamente os sensores existentes no robô. Além disso, são incorporados blocos que trabalham os conceitos de variáveis, operações lógicas e aritméticas e de estruturas de controle de fluxo (estruturas de repetição e condicionais). Desta forma, a seção de funcionalidades da visão LERO Adolescente apresenta sete grupos de funções.

Os grupos Movimento, Aparência e Som continuam com os mesmos blocos da visão LERO Criança. O grupo Controle (Figura 6A) possui além do bloco de inicialização (bandeira verde), as estruturas usuais de programação de controle de fluxo (condicionais e de repetição). As estruturas condicionais disponibilizadas são a condicional simples (se-então) e a condicional composta (se-então-senão). As estruturas de repetição disponibilizadas são: uma estrutura para repetição de um número conhecido de vezes (repita $\mathrm{N}$ vezes), repetição até que uma condição seja atendida (repita até que) e uma estrutura com loop infinito (sempre). No caso da estrutura sempre é necessário incluir uma condição de parada. Estas estruturas são bastante 
VII Congresso Brasileiro de Informática na Educação (CBIE 2018)

Anais do XXIX Simpósio Brasileiro de Informática na Educação (SBIE 2018)

utilizadas no ensino de programação e robótica para alunos do ensino médio e como curso introdutório em cursos técnicos e de graduação.

No grupo Variáveis (Figura 6B), foram definidas algumas variáveis lógicas que representam o estado do robô. Estas variáveis são usadas em conjunto com as estruturas de controle de fluxo e nas operações lógicas. As variáveis utilizadas para refletir o estado do robô são: Em Movimento, Parado, Virando e Perto de Obstáculo, que permitem ao usuário, usando o raciocínio lógico, trabalhar com valores lógicos (verdadeiro/falso) para possíveis tomadas de decisões.

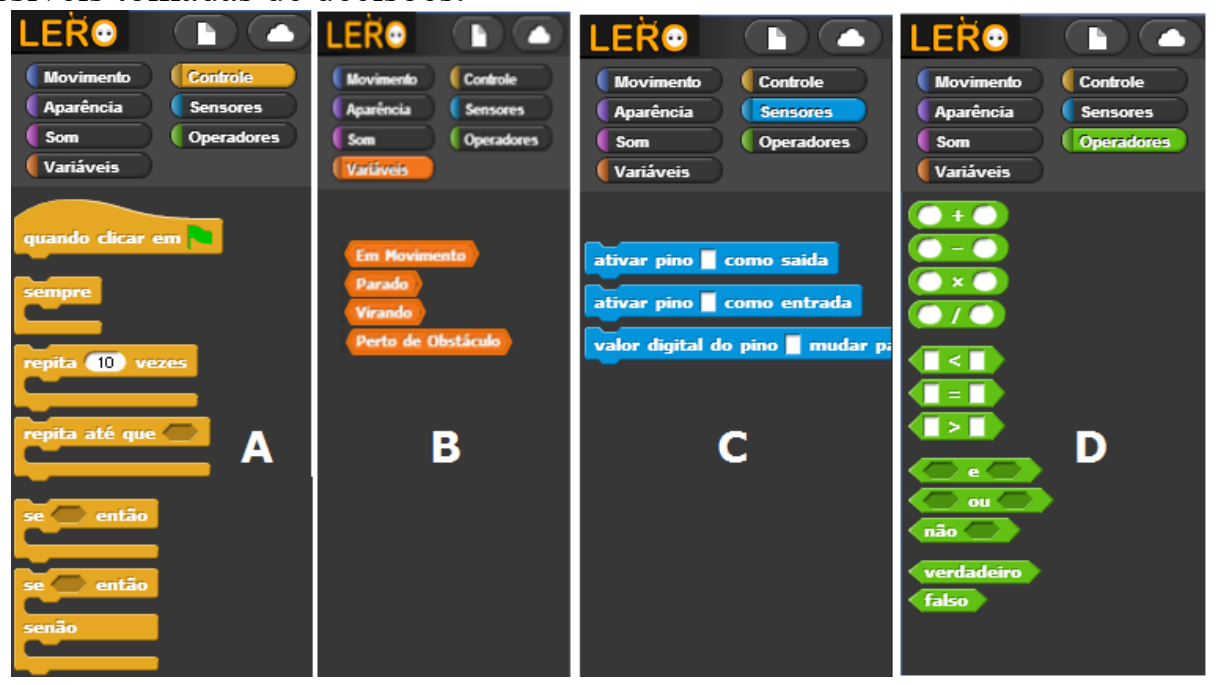

Figura 6. Aba de funcionalidades do LERO Adolescente.

No grupo Sensores (Figura 6C) foram disponibilizados alguns blocos com comandos básicos que permitem operar diretamente os sensores existentes no robô. Os comandos disponíveis permitem definir um determinado pino como entrada ou saída de um sensor e, quando for um pino de entrada, permite definir um valor para ser enviado ao sensor.

Por fim, o grupo de funções chamado Operadores (Figura 6D), possui blocos com operações aritméticas básicas, operações relacionais, operações e constantes lógicas. Estas operações podem ser combinadas com as variáveis de estado do robô e com valores numéricos na construção de códigos (roteiros) mais elaborados para a manipulação do robô.

A Figura 7A apresenta um roteiro desenvolvido com a visão LERO Adolescente. Neste roteiro, o aluno ativa o dispositivo conectado no pino 12 do robô, onde existe uma lâmpada de Led conectada. Depois disso foi criada uma estrutura de repetição para executar cinco vezes as seguintes ações: acender LED, andar dez passos, apagar LED, virar à direita, acender LED e andar mais cinco passos.

A visão LERO Extremo foi desenhada para usuários experientes. A característica mais importante desta visão é a capacidade de criar ações e disponibilizar estas ações na forma de blocos de programação para as diversas visões do LERO. Esta característica é que confere o caráter extensível ao ambiente LERO.

De forma a ilustrar a extensibilidade do ambiente, considere o desenvolvimento da funcionalidade do bloco Ande $\mathrm{N}$ Passos, disponível tanto nas visões LERO Criança (Figura 5A) e LERO Adolescente (Figura 7A). Esta ação foi codificada na versão LERO 
VII Congresso Brasileiro de Informática na Educação (CBIE 2018)

Anais do XXIX Simpósio Brasileiro de Informática na Educação (SBIE 2018)

Extremo utilizando blocos de programação de baixo nível. Esta ação, aparentemente simples do robô, é codificada através de algumas dezenas de bloco de construção de baixo nível. Devido a limitação de espaço, não apresentamos todos os comandos necessários a execução da ação de andar. A Figura $7 \mathrm{~B}$ mostra apenas parte do código que aciona os pinos digitais que controlam os motores servos das rodas esquerda e direita para realizar a referida ação. Esta funcionalidade de produzir novos blocos utilizando o LERO Extremo e disponibilizar estes blocos para os demais ambientes é o que confere o caráter extensível do LERO.
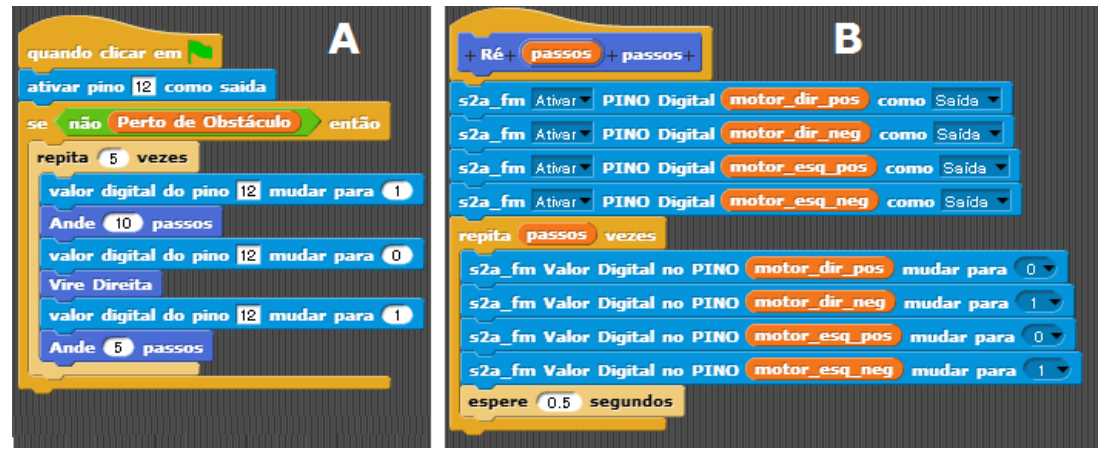

Figura 7. Roteiro desenvolvido com a visão LERO Extremo.

\section{Conclusões e Trabalhos Futuros}

Este artigo apresentou o Laboratório Remoto de Robótica Educacional (LERO). O objetivo do projeto LERO é disponibilizar, de forma livre e gratuita, uma ferramenta que permita a um público-alvo variado trabalhar com conceitos abstratos, raciocínio lógico, habilidades cognitivas e estruturas complexas da linguagem de programação utilizando um ambiente robótico remoto e acessado via Web. O LERO se diferencia da maioria das iniciativas de robótica educacional, virtual ou remota, por apresentar duas características importantes, que são a adaptabilidade e a extensibilidade do ambiente.

A adaptabilidade é alcançada através do oferecimento de diversas visões do sistema através de aplicações clientes configuradas para o nível de conhecimento e experiência do usuário, considerando as diversas faixas etárias e o tipo de experimento disponibilizado. As diferentes visões são criadas no topo de uma infraestrutura comum e utilizam a mesma metáfora para a interface gráfica com o usuário. Esta característica atenua a curva de aprendizagem da ferramenta e facilita o oferecimento de novas visões para o sistema. A extensibilidade é garantida pela capacidade de criação de novos blocos utilizando a própria biblioteca do LERO, tendo como apoio pedagógico um tutorial disponível no ambiente.

Os trabalhos futuros irão abordar alguns aspectos relevantes no componente servidor da arquitetura LERO. Questões como acesso concorrente ao laboratório, validação do perfil dos usuários, sistema de reservas, registro de experimento realizados são funcionalidades que precisam ser implementados e disponibilizadas para tornar o ambiente completamente funcional em grande escala.

No que tange a validação da proposta como forma de aprendizagem, pretende-se realizar um experimento com a utilização de questionários de pré-teste e pós-teste, para a verificação da eficiência da proposta, com a participação de alunos de três faixa etárias, contemplando as visões do LERO: criança, adolescente e extremo. 
VII Congresso Brasileiro de Informática na Educação (CBIE 2018)

Anais do XXIX Simpósio Brasileiro de Informática na Educação (SBIE 2018)

\section{References}

Angulo, I., Zubía, J. G., Jayo, U. H., Uriarte, I., Gil, L. R., Orduña, P. and Pieper G. M. (2017) "RoboBlock: A Remote Lab for Robotics and Visual Programming", In: Proceedings of 4th Experiment@ International Conference, p. 109-110, Faro, Portugal.

Bagnall B. (2007) "Maximum LEGO NXT: Building Robots with Java Brains". Ed. Variant Press.

Bezerra Neto, R. P., Rocha, D. P., Santana, A. M. and Souza, A. A. S. (2015) "Robótica na Educação: Uma Revisão Sistemática nos Últimos 10 anos" XXVI Simpósio Brasileiro de Informática na Educação, p. 386-393, Maceió.

Fiorio, R., Esperandim, R. J., Silva, F. A., Varela, P. J., leite, M. D. and Reinaldo, F. A. F. (2014) "Uma experiência prática da inserção da robótica e seus benefícios como ferramenta educativa em escolas públicas". In: XXV Simpósio Brasileiro de Informática na Educação, III Congresso Brasileiro de Informática na Educação, Vol. 25. No. 1, p. 1223-1232, Recife.

Firmata (2016) Arduino Disponível em: https://www.arduino.cc/en/reference/firmata. Acesso em: 10 de agosto de 2016.

Gil, A.C. Como Elaborar Projetos de Pesquisa. $5^{\text {a }}$ ed. São Paulo: Atlas S.A., 2000.

Granado, E., Colmenares W., Pérez, O. and Cataldo G. (2013) "Remote Experimentation Using Mobile Technology" IEEE Latin America Transactions, Vol. 11, No. 4, p. 1121-1126.

Iturrate, I., Martín G., Zubia J. G., Angulo, I., Dziabenko, O., Orduña, P., Alves, G. and Fidalgo, A. (2013) "A Mobile Robot Platform for Open Learning based on Serious Games and Remote Laboratories", In: 1st International Conference of the Portuguese Society for Engineering Education, p. 1-7, Porto, Portugal.

Oliveira, G. A. A. D., Bettio, R. W., Rodarte, A. P. M., Braz, J. E. and Ferrari F. B. (2014) "GrubiBots Educacional: jogo para o ensino de algoritmos na educação básica”, In: XVIII Simpósio Brasileiro de Informática na Educação, Vol. 25, No. 1, p. 584-592, São Paulo.

Pio, J. L. D., Castro, T. H. C. D. and JÚNIOR, A. N. D. C. (2007) "A Robótica Móvel como Instrumento de Apoio à Aprendizagem de Computação" In: XVIII Simpósio Brasileiro de Informática na Educação, p. 197-206, São Paulo.

S2A (2016) MrYsLab/s2a_fm. Disponível em: https://github.com/MrYsLab/s2a_fm, Acesso em: 21 Maio 2016.

SNAP (2016) Snap! (Build Your Own Blocks) 4.0. Snap! Disponivel em: http://snap.berkeley.edu/, Acesso em: 21 Maio 2016.

Souza, M. B., Netto, J. F. M., Alencar, M. A. S., Silva, M. M. (2011) “Arcabouço de um Ambiente Telerobótico Educacional Baseado em Sistemas Multiagente". In: Anais do XXII Simpósio Brasileiro de Informática na Educação, Vol. 1, p. 680-689.

Yorinks, A. (2014) "A Scratch 2 and Snap! 4 Hardware Extension for Arduino MicroControllers" http://wiki.computacaonaescola.ufsc.br/images/a/ab/S2a_manual.pdf. 